\title{
Early Communication Intervention with Young Children with Pierre Robin Sequence
}

\author{
Lisl Fair and Brenda Louw \\ Centre for Early Intervention in Communication Pathology \\ Department of Communication Pathology \\ University of Pretoria
}

\begin{abstract}
Young children with Pierre Robin sequence are at considerable risk to develop delayed or disordered communication development. This study investigated the effectiveness of early communication intervention with four young children with Pierre Robin sequence, aged 5 to 28 months. The Proportional Change Index (Wolery, 1983) was used to determine the amount of child progress that took place during the intervention period. The results indicated that regular early communication intervention sessions over an extended period of time produced positive results, especially for expressive language abilities. The presence of a slight hearing loss due to otitis media, seemed to have influenced the effectiveness of early communication intervention. One subject displayed an associated disorder and evidenced the slowest rate of development for receptive and expressive language abilities as well as a limited phonetic repertoire for consonants. All but one subject had limited phonetic repertoires possibly due to velopharyngeal incompetence. Early communication intervention services should be delivered regularly over an extended period of time and the hearing abilities and speech production shills of young children with Pierre Robin sequence should be followed closely during early communication intervention.
\end{abstract}

\section{OPSOMMING}

Jong hinders met Pierre Robin-volgpatroon vertoon risikofaktore om vertraagde of afwykende kommunikasie-ontwikkeling te hê. Hierdie studie het die effektiwiteit van vroeë-kommunikasie-intervensie met vier jong kinders met Pierre Robin-volgpatroon, tussen die ouderdomme van 5 en 28 maande, ondersoek. Die Proporsionele Veranderings-indeks (Wolery, 1983) is aangewend om die mate waarin die proefpersone tydens die intervensie-tydperk gevorder het, aan te dui. Die resultate het aangetoon dat gereelde vroeë-kommunikasie intervensie sessies oor 'n uitgebreide tydperk, veral vir ekspressiewe taalvaardighede, positiewe resultate lewer. Die teenwoordigheid van' $n$ geringe gehoorverlies as gevolg van otitis media, het moontlik die effektiwiteit van vroeë-kommunikasie-intervensie beïnvloed. Een proefpersoon het Pierre Robin-volgpatroon en ' $n$ geassosieerde afwyking getoon en die resultate het aangetoon dat haar ontwikkelingstempo vir reseptiewe en ekspressiewe taalvermoëns die stadigste was en ook dat sy ' $n$ beperkte fonetiese repertoire vir konsonante getoon het. Drie uit die vier proefpersone het beperkte fonetiese repertoires getoon, moontlik as gevolg van velofaringeale onbevoegdheid. Vroë̈-kommunikasie-intervensie-dienste aan jong kinders met Pierre Robin-volgpatroon behoort op ' $n$ gereelde basis oor ' $n$ uitgebreide tydperk gelewer te word en die gehoorvermoëns en spraakproduksie-vermoëns van hierdie kinders moet gemonitor word gedurende intervensie.

KEY WORDS: Pierre Robin sequence, early communication intervention, effectiveness

In the past two decades young children with communication disorders have received increased attention within the field of Communication Pathology (Guralnick, 1997). Any factor influencing the way a child interacts with his environment can be considered to be a potential risk factor contributing to a developmental delay (Rossetti, 1996). Infants with Pierre Robin sequence are classified as highrisk infants since a number of risk factors are associated with Pierre Robin sequence (Elliot, Studen-Pavlovich \& Ranalli, 1995).

Three distinct symptoms mark the presence of Pierre Robin sequence in a young child, namely mandibular hypoplasia, glossoptosis as well as a wide U-shaped cleft of the palate (Shprintzen \& Bardach, 1995), which cause a number of medical problems' for these children. Elliot et al. (1995) list the following medical complications frequently occurring in young children with Pierre Robin sequence: airway obstruction, hypoxia, respiratory infections, otitis media and feeding problems like an insufficient sucking pattern and aspiration. In addition to these medical complications, children with Pierre Robin sequence may also exhibit problems like cerebral palsy (BuIl, Givan, Sadove, Bixler \& Hearn, 1990), congenital heart problems, cognitive impairments and visual problems (Sadewitz, 1992). The medical care necessitated by these early medical complications and associated disorders often require that infants with Pierre Robin sequence are hospitalized for prolonged periods of time (Savage, 1997).

The communication development of young children with Pierre Robin sequence is traditionally described as being characterised by the same impairments as that of children with cleft lip and palate, namely: velopharyngeal incom- 
petence, nasal emission, hypernasality, compensatory articulation patterns and delayed language development (McWilliams, Morris \& Shelton, 1990). Infants with cleft lip and palate are classified as presenting an established risk for communication disorders (Rossetti, 1996), but the combination and magnitude of the risk factors present in the case history of most young children with Pierre Robin sequence can have an even greater influence on their communication development. A combination of established, biological and environmental risk factors are often associated with young children with Pierre Robin sequence and may have a negative influence on the way a child with Pierre Robin sequence interacts with his environment. These risk factors are summarised in Table 1.

Children with Pierre Robin sequence are described indepth in the literature due to the complexity of the disorder (Sadewitz, 1992) and special attention is given to research on the early medical complications accompanying Pierre Robin sequence (Bull et al., 1990; Elliott et al., 1995; Sadewitz, 1990). In spite of the number of studies on the medical complications of Pierre Robin sequence and the atrisk status of young children with Pierre Robin sequence, a dearth in the literature exists regarding information about the outcome of their communication development. An early study conducted by Pashayan and Lewis in 1984 provided information regarding the speech- and language development of children with isolated Pierre Robin sequence as well as of children with Pierre Robin sequence and an additional syndrome. The speech- and language development of children with isolated Pierre Robin sequence was found to be impaired and the speech-and language development of those children with Pierre Robin sequence and an additional syndrome was found to be even more impaired and delayed than those with isolated Pierre Robin sequence. Since the study conducted by Pashayan \& Lewis (1984), limited research was reported on the communication development of young children with Pierre Robin sequence, rendering their work to be a valuable source of information on the early communication development of these children.

According to Shprintzen and Bardach (1995) additional syndromes exist in more than half of all Pierre Robin sequence cases, such as Stickler syndrome (34\% of all Pierre Robin sequence cases) and Velocardial Facial syndrome (11\% of all Pierre Robin sequence cases). The presence of an additional syndrome in young children with Pierre Robin sequence places them at greater risk to display delayed or disordered communication development. Speech-language therapists delivering services to young children are advised to take cognisance of the fact that a relatively high number of children with Pierre Robin sequence may have an additional syndrome and to provide services that are responsive to the individual needs of each child (Shprintzen \& Bardach, 1995).
The presence of a hearing impairment can also negatively influence the communication development of young children with Pierre Robin sequence. Handžič, Bagatin, Subotič and Čuk (1995) found that these children are at-risk for a congenital sensory-neural, conductive or mixed hearing loss, with or without the presence of congenital malformations of the ear. These authors also found that children with Pierre Robin sequence have a slight hearing loss due to middle ear effusions. Elliot et al. (1995) further indicate that $90,9 \%$ of all children with Pierre Robin sequence have at least one episode of otitis media. The presence of a slight hearing loss may have a negative influence on the communication development of a child since receptive language development is dependent on adequate and constant auditory input (Friel-Patti, 1990).

Due to the established risk displayed by young children with Pierre Robin sequence, early communication intervention seems to be the only viable option in considering treatment alternatives. Early communication intervention is a relatively new field of study within the discipline of Communication Pathology and is currently viewed as the best form of intervention for at-risk children (Rossetti, 1996). Early communication intervention is aimed at the prevention of communication disorders by facilitating communication development and optimising developmental outcome through parent centred therapy (Savage, 1997; Kritzinger, Louw \& Hugo, 1996).

The revision of the South African Speech-Language Hearing Association's Code of Ethics in 1997, placed renewed focus on the issue of accountable and effective service delivery in South Africa (SASHLA, 1997). The revised Code of Ethics emphasises the fact that clients should benefit from service delivery and that professionals should adhere to their professional responsibility in conducting speech-language therapy services (SASHLA, 1997). According to Carney (1996) and Boston (1994) accountable and effective service delivery is important since data from effective service delivery can be used in advocacy activities like motivating the allocation of funds from medical aid schemes and donor organisations. The early communication intervention services rendered by speechlanguage therapists to young children with Pierre Robin sequence should be accountable and effective to ensure that these children gain maximum benefit from intervention and reach their full developmental potential.

The provision of early communication intervention services to at-risk children is strongly advocated and the effectiveness of these practices is a current topic in literature (Lee \& Khan, 1997). Several authors concur that early communication intervention programmes are indeed effective, but factors influencing the effectiveness of these programmes have been identified (Rossetti, 1996; Savage,

TABLE 1: Risk factors associated with Pierre Robin sequence(compiled from Rossetti, 1996; Sadewitz, 1992 and Savage, 1997).

\begin{tabular}{|c|c|c|}
\hline $\begin{array}{l}\text { Established } \\
\text { risk factors }\end{array}$ & $\begin{array}{l}\text { Environmental } \\
\text { risk factors }\end{array}$ & $\begin{array}{l}\text { Biological } \\
\text { risk factors }\end{array}$ \\
\hline $\begin{array}{l}\text { - Pierre Robin sequence } \\
\text { - Associatied disorders }\end{array}$ & $\begin{array}{l}\text { - Prolonged and multiple } \\
\text { hospitalization } \\
\text { - Disruption of parent-infant } \\
\text { interaction } \\
\text { - Family stressors }\end{array}$ & $\begin{array}{l}\text { - Respiratory problems } \\
\text { - Feeding problems } \\
\text { - Failure to thrive } \\
\text { - Recurrent otitis media }\end{array}$ \\
\hline
\end{tabular}


1997; Guralnick, 1997). Factors influencing the effectiveness of early intervention include: the age of onset of intervention (the younger, the more benefit), degree of involvement of the parents (the more involved the greater the benefit), home and centre based components included in the programme (both should ideally be included) and the quality of intervention services (the higher the quality the higher the benefits) (Rossetti, 1996; Savage, 1997; Guralnick, 1997). Speech-language therapists delivering early communication intervention services to young children with Pierre Robin sequence should take cognisance of these factors and incorporate them into service delivery to ensure that a high standard of service delivery is maintained.

The measurement of effective service delivery in early communication intervention is currently a controversial subject in literature (Lee \& Khan, 1997), since the amount of child progress has traditionally been used to determine the effect of early intervention. By simply comparing preand post intervention data to determine child progress, the effect of natural maturation is not accounted for and the comparison may yield a false picture of the effect of intervention on the development of the child (Rossetti, 1996). Lee and Khan (1997) suggest that the natural maturation of the child as well as the child's rate of development prior to intervention should be taken into consideration when determining child progress and programme effectiveness. Any formula used to determine child progress and programme effectiveness must account for these two factors, to ensure that the progress in development is due to intervention and not only to natural maturation (Lee \& Khan, 1997).

Currently several methods of measuring the developmental progress of children in early communication intervention programmes, exist. These include developmental age comparisons, developmental quotient comparisons, indexes of change, actual-predicted score comparisons and modelling individual growth (Lee \& Khan, 1997). In a study conducted to determine the most effective way to determine child progress and programme effectiveness Lee \& Khan (1997) applied all of these methods to a sample of children who received early intervention. Their results indicated that using an index of change, namely the Proportional Change Index (PCI), which was developed by Wolery (1983), provides the most appropriate way of measuring child progress and programme effectiveness in early intervention. By measuring change in the rate of development, this method accounts for natural maturation as well as the child's rate of development prior to intervention and will therefore provide an accurate indication of the progress a child has made in intervention.

The early communication intervention approach currently used in the Centre for Early Intervention in Communication Pathology, Department of Communication Pathology, University of Pretoria is a parent centred approach and was developed as an appropriate and effective approach to early communication intervention by Louw \& Hugo (1987). It includes the use of three intervention strategies namely education, counselling and training of parents, and intervention sessions are conducted monthly due to the distances parents often have to travel as well as the limited number of speech-language therapists providing early intervention services in South Africa (Louw \& Hugo, 1987; Louw, Hugo, Kritzinger \& Pottas, 1997).

Speech-language therapists in South Africa applying this approach and aiming to provide quality services to the young children with Pierre Robin sequence need to be aware of matters pertaining to the measurement of effectiveness in early communication intervention. Rossetti (1996) stresses the importance of accountable service delivery in early communication intervention by referring to the term best practice. He concludes that best practice can only be achieved by carefully measuring programme outcomes. In order to establish whether the early communication intervention approach currently being used in South Africa for the treatment of young children with Pierre Robin sequence constitutes best practice it is necessary to measure the outcome of intervention. The measurement of the effectiveness of early communication intervention with young children with Pierre Robin sequence may provide an indication of the appropriateness and possible shortcomings in the approach currently followed.

The aim of this study is to establish whether early communication intervention with young children with Pierre Robin sequence is effective.

\section{METHODOLOGY}

\section{AIMS}

The purpose of this study was to determine the effectiveness of early communication intervention with four young children with Pierre Robin sequence and the following subaims were formulated:

- the measurement of the effectiveness of early communication intervention for the receptive language abilities of the subjects,

- the measurement of the effectiveness of early communication intervention for the expressive language abilities of the subjects,

- the measurement of the effectiveness of early communication intervention for the cognitive abilities of the subjects and,

- the measurement of the effectiveness of early communication intervention for the speech production abilities of the subjects.

\section{RESEARCH DESIGN}

An ABA quasi-experimental case study research design was used to measure the progress of the subjects in intervention because all the variables in the study could not be controlled (McBurney, 1994). The phases of the research process are graphically depicted in Figure 1 and included the following: the $\mathrm{A}_{1}$ phase consisted of the pre-treatment assessment conducted in the Clinic for High Risk Infants (CHRIB) at the Centre for Early Intervention in Communication Pathology, Department of Communication Pathology, University of Pretoria. The B phase consisted of early communication intervention, which the subjects received for varying periods of time and the $A_{2}$ phase consisted of the post-treatment assessment conducted in the home of each subject. This research design allows for the description of the individual performance of each subject but the design does not allow for generalisation of the findings (McBurney, 1994).

\section{SUBJECTS}

The subjects (Ss) were extracted retrospectively from file data at the Clinic for High Risk Babies (CHRIB), which 


\begin{tabular}{|c|}
\hline PHASES IN MHE RESEARCH PROCESS \\
Phase A $_{1}$ \\
Pre-treatment assessment conducted at CHRIB \\
\hline $\begin{array}{c}\text { Phase B } \\
\text { Early communication intervention }\end{array}$ \\
Post-treatment assessment conducted at the home of \\
each subject
\end{tabular}

FIGURE 1: Phases in the research process

serves as a diagnostic and intervention facility for the Centre for Early Intervention in Communication Pathology, aimed at service delivery to high risk infants and toddlers and their families. A total of four subjects were available when the following criteria were applied: the subjects must have been diagnosed as having Pierre Robin sequence and they must have been between 5 and 30 months of age during the post-treatment assessment. The following factors were not considered during the selection procedure: number of early communication intervention sessions received, the presence of associated disorders and slight to moderate prematurity. The absence of associated disorders were not included in the selection criteria since Shprintzen and Bardach (1995) found that more than fifty percent of children with Pierre Robin sequence also display associated disorders. Slight to moderate prematurity was also not considered since Caouette-Laberge, Bayet and Larocque (1994) indicated that up to eight percent of infants with Pierre Robin sequence are born prematurely.

The four subjects' ages ranged from 5 months to 28 months and all received early communication intervention for varying periods, initiated after each subject's pretreatment assessment. One subject (S4) displayed an associated disorder (Velocardial-facial syndrome) as well as slight prematurity and another (S1) evidenced moderate prematurity. All of the subjects had had episodes of otitis media. Table 2 provides a detailed description of the subjects.

\section{PROCEDURE}

\subsection{ASSESSMENT AND DATA COLLECTION}

Each subject underwent comprehensive pre- and posttreatment assessments utilising the CHRIB Evaluation Protocol (Louw \& Kritzinger, 1994). The CHRIB Evaluation Protocol (Louw \& Kritzinger, 1994) covers all aspects of early communication development and includes the use of several other published evaluation instruments, as well as clinical guidelines for the interpretation of descriptive data. The pre-treatment assessments of all four subjects were conducted in CHRIB by the same experienced clinicians, whereas the post-treatment assessments were carried out in the homes of the subjects by the first author. The posttreatment assessments were conducted in the homes of the subjects as the home environment is considered to be a naturalistic context and a more reliable representation of the child's functioning can be obtained in the context of the child's home (Rossetti, 1996). The fact that the pre- and post-treatment assessments were not conducted in the same setting implies that an extra variable was introduced, but as the data used in this study was part of a wider research project (Fair, 1997) this variable could not be controlled.

During both the pre- and post-treatment assessments an interview was conducted with the parents of the subjects in order to obtain background information and the subjects' communication- and general developmental skills were elicited in a controlled play context. Infant behaviour was recorded using evaluation instruments such as the Rossetti Infant Toddler Language Scale (Rossetti, 1990), the Developmental Assessment Schema (DAS) (Anderson, Nelson \& Fowler, 1978), as well as the Developmental Activities Screening Inventory II (DASI-II) (Fewell \& Langley, 1984). Infant behaviours such as vocalizations and verbalizations were also recorded and used as descriptive data. Video- and audio-recordings were made during both the pre- and post-treatment assessments utilizing a

TABLE 2: Description of the subjects (n=4)

\begin{tabular}{|l|c|c|c|c|}
\hline Characteristics & Subject 1 & Subject 2 & Subject 3 & Subject 4 \\
\hline Gender & Male & Female & Female & \begin{tabular}{c} 
Femále \\
\hline Pre-treatment age in months
\end{tabular} \\
\hline Post-treatment age in months & 25 & $\mathbf{9}$ & 10 & 5 \\
\hline Diagnosis & $\begin{array}{c}\text { Pierre Robin } \\
\text { sequence }\end{array}$ & $\begin{array}{c}\text { Pierre Robin } \\
\text { sequence }\end{array}$ & $\begin{array}{c}\text { Pierre Robin } \\
\text { sequence }\end{array}$ & $\begin{array}{c}\text { Pierre Robin } \\
\text { sequence }\end{array}$ \\
\hline Prematurity & Moderate & None & None & Slight \\
\hline Associated disorders & None & None & None & $\begin{array}{c}\text { Velocardial- } \\
\text { Facial syndrome }\end{array}$ \\
\hline Medical problems & Otitis media & Otitis media & Otitis media & Ótitis media \\
\hline ECI received (months) & 14 & 19 & 9 & 5 \\
\hline ECI received (sessions) & 13 & $\mathbf{1 4}$ & 1 & 2 \\
\hline ECI received at & Private Practitioner & CHRIB & CHRIB & CHRIB \\
\hline
\end{tabular}

Key: $\mathrm{ECI}=$ Early Communication Intervention 
Panasonic R33 VHS-C Movie Camera and a Sakyno SK-2100 Portable Cassette Recorder. These recordings were used to accurately document and describe infant behaviours.

After the data was collected it was processed by using guidelines and procedures described in the published materials and literature in order to determine the developmental levels of the subjects and to describe their behaviour accurately (Rossetti, 1990; Anderson et al., 1978; Fewell \& Langley, 1984; McWilliams et al., 1990; Shprintzen \& Bardach, 1995). For the purpose of this study only evaluation areas pertaining to communication development were considered since the main focus of early communication intervention is the facilitation of communication skills (Louw \& Kritzinger, 1991). These areas were receptive and expressive language development, cognitive development and the speech production abilities of the subjects. Cognitive development was included in the study as Rossetti (1996) indicated that in children younger than twenty four months of age the development of language and cognition is so integrated that it cannot be separated and Louw \& Kritzinger (1991) list the facilitation of cognitive development as an aim for early communication intervention.

A data collection form was compiled and the following information was copied from the pre-and post-treatment evaluation data in order to analyse the data: the developmental ages of the subjects yielded by the Rossetti Infant Toddler Language Scale (Rossetti, 1990) for receptive and expressive language abilities, the developmental age of the subjects for cognitive development, determined by the DASIII (Fewell \& Langley, 1984) and a qualitative description of the subjects' phonetic repertoires for consonants.

Although the CHRIB Evaluation Protocol (Louw \& Kritzinger, 1994) allows for eliciting and describing information regarding the type and number of consonants, syllable structure as well as the level of vocalizations during the evaluation of speech production abilities, only the type and number of consonants were considered in this study. The type and number of consonants were selected and qualitatively described as children with Pierre Robin sequence often display limited phonetic repertoires and experience problems in producing pressure consonants and fricatives (McWilliams et al., 1990, Shprintzen \& Bardach, 1995).

\subsection{DATA ANALYSIS}

The data regarding the receptive, expressive and cognitive development of the subjects on the data collection form was analysed and compared using the Proportional Change Index (PCI) (Wolery, 1983) to determine the amount of child progress that took place. The PCI is calculated using the following formula:

$$
\begin{aligned}
\mathrm{PCI} & =\text { (Developmental gain in months } \\
& \div \text { Time in intervention in months) } \\
& \div \text { (Pretest developmental age } \\
& \div \text { Pretest chronological age) }
\end{aligned}
$$

After calculation the PCI (Wolery, 1983) yields a numerical statement of the relationship between the rate of development prior to intervention and the rate of development during intervention. A score of 1.0 indicates that the rate of development prior to intervention is identical to the rate of development during intervention, while a score of more than 1.0 shows that the rate of development during intervention is faster than the rate of development prior to intervention. A score of less than 1.0 indicates that the rate of development during intervention is slower than the rate of development prior to intervention. If the PCI score surpasses 1.0 the programme is regarded as effective (Lee \& Khan, 1997; Wolery, 1983).

The data on the data collection form regarding the phonetic repertoires of the subjects was analysed by comparing the number of consonants that the subjects used during the pre- and post-treatment assessments, as well as listing the different consonants that the subjects used during the pre-and post-treatment assessments. As clinical guidelines for assessing the development of consonants are not readily available and a developmental age level pertaining to this area of communication development could therefore not be established, the PCI (Wolery, 1983) was not used in the analyses of the phonetic repertoires of the subjects. Oller, Eilers, Steffens, Lynch and Urbano (1994) describe alternative approaches to measuring the development of consonants in young children but as the data used in this study was part of a wider research project (Fair, 1997), the CHRIB Evaluation Protocol (Louw \& Kritzinger, 1994) was deemed to be appropriate to assess this area of development.

The results of the receptive, expressive and cognitive developmental progress of the subjects as well as the qualitative description of the phonetic repertoires of the subjects were then further analysed by using descriptive statistics in order to display the results graphically in the form of bar charts.

\section{RESULTS AND DISCUSSION}

The developmental age levels of the subjects pertaining to their receptive and expressive language development, as well as cognitive development, is presented in Figure 2 in order to provide an overview of the development of the subjects during the pre- and post-treatment assessments. Figure 3 indicates the chronological ages of the subjects at the time of the pre- and post-treatment assessments.

All the subjects showed progress in receptive and expressive language development as well as cognitive development from the pre-treatment assessment to the posttreatment assessment, as indicated in Figure 2. During the post-treatment assessment subject one and four evidenced delayed development in receptive and expressive language development as well as in cognitive abilities (See Figures 2 and 3). Subject two's developmental age for receptive- and expressive language development as well as cognitive abilities during the post-treatment assessment was slightly above her chronological age whereas subject three evidenced appropriate development for cognitive abilities and receptive language abilities but showed a delay in her expressive language development during the posttreatment assessment (See Figures 2 and 3)

\section{RECEPTIVE LANGUAGE ABILITIES}

Figure 4 indicates that two of the four subjects (Ss1 and 2) showed faster rates of development during intervention than prior to intervention, as their PCI scores were 1.14 and 1.42 respectively. Subjects three and four showed slower receptive language development during intervention than prior to intervention, their scores being 0.91 and 0.8 respectively. 
The fact that subjects one and two's rate of development was accelerated during intervention may be attributed to the number of early communication intervention sessions they attended, which amounted to thirteen and fourteen respectively (See Table 2). Subjects three and four only attended one and two early communication intervention sessions respectively and were also involved in intervention for a shorter period of time (See Table 2). These results seem to indicate that greater benefit is derived from early communication intervention if sessions are presented at least once a month over an extended period of time. This finding is in agreement with the early communication intervention approach used at CHRIB (Louw and Kritzinger, 1991) during which early communication intervention is conducted monthly from when the child enters the programme until approximately twenty four months of age after which intervention becomes more child centered and is provided on a twice monthly or weekly basis.

All the subjects displayed episodes of otitis media during the intervention period and the slight hearing loss associated with otitis media could have had a negative influence on the rate of their receptive language development (Friel-Patti, 1990). Subject four, who obtained the lowest score had chronic otitis media with effusion during the whole intervention period and the severity of the condition could have influenced her rate of development during the intervention period in particular. In addition to the otitis media, her rate of development for receptive language could also have been influenced by the Velocardial-facial syndrome she displays, since Shprintzen and Bardach (1995) indicated that children with Velocardial-facial syndrome exhibit delayed language development, as well as by the fact that she had only attended two therapy sessions.

\section{EXPRESSIVE LANGUAGE ABILITIES}

Figure 5 illustrates the rate of development of the subjects' expressive language abilities. Their PCI scores

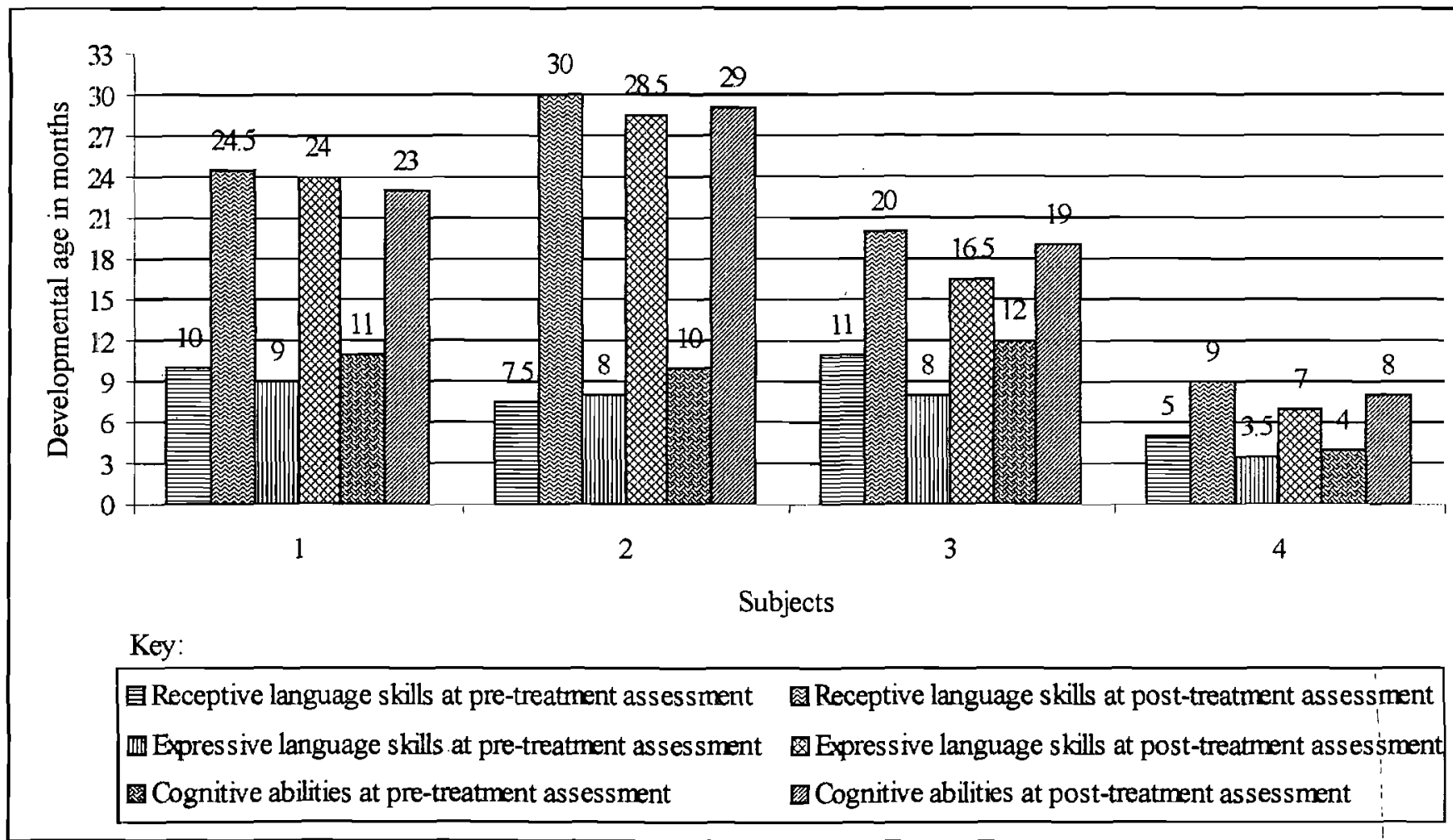

FIGURE 2: Developmental ages of the subjects

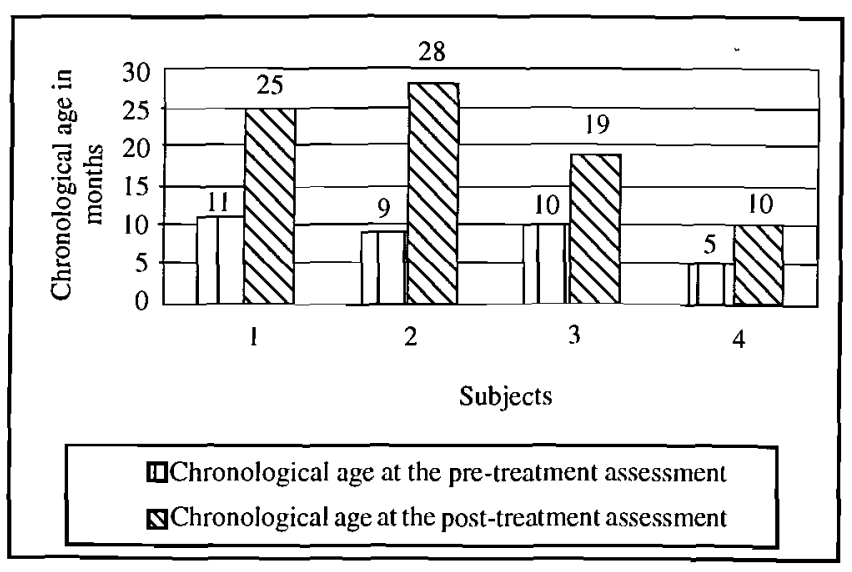

FIGURE 3: Chronological ages of the subjects

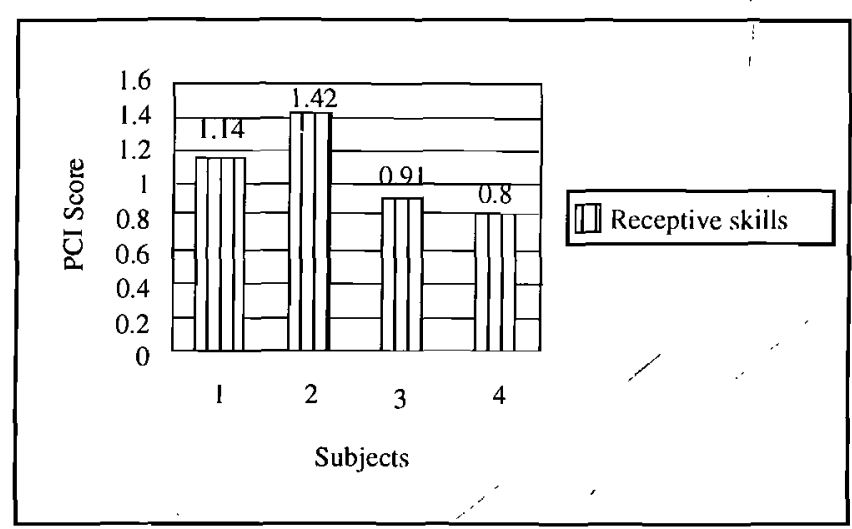

FIGURE 4: Rate of development for receptive language abilities $(n=4)$ 
(Wolery, 1983) indicate that three of the four subjects displayed accelerated rates of development during intervention ( $1.31,1.21$ and 1.18 respectively). The fourth subject's rate of development remained the same (1.0).

The relatively fast rate of development of expressive language abilities displayed by the first three subjects may be due to the respective periods of early intervention they received. The two subjects who attended the most early communication intervention sessions (Ss 1 and 2) showed the most accelerated rate of expressive language development. The results of the subjects' rate of expressive language development confirms the results of the rate of receptive language development and indicates that the frequency and duration of intervention has an influence on the effectiveness of intervention. It is possible that the subjects could have derived more benefit from intervention if the sessions were conducted once weekly, as is advocated by international literature (Guralnick, 1997; Rossetti, 1996; Lee \& Khan, 1998), but challenges such as geographical distribution of available services and the number of speechlanguage therapists in the South African context, necessitated a revision of the recommended practice and resulted in early communication intervention sessions being conducted once monthly (Louw et al., 1997).

Subject four showed the same rate of development for expressive language abilities prior to and during intervention. The fact that she has Velocardial-facial syndrome could have influenced her stagnation in rate of development since Pashayan and Lewis (1984) indicated that the expressive language abilities of children with Pierre Robin sequence and associated disorders are more delayed than those of children displaying Pierre Robin sequence only. Subject four's slow rate of development for receptive language abilities could also have had a negative influence on her expressive language abilities since the development of expressive language is considered to be dependent on the development of receptive language (Owens, 1995).

\section{COGNITIVE ABILITIES}

According to figure 6 the results of the subjects' rate of cognitive development indicates that three of the four subjects had a slower rate of development during intervention than prior to intervention $(0.86,0.9$ and 0.65 respectively). Subject four had the same rate of development during intervention than prior to intervention (1.0).

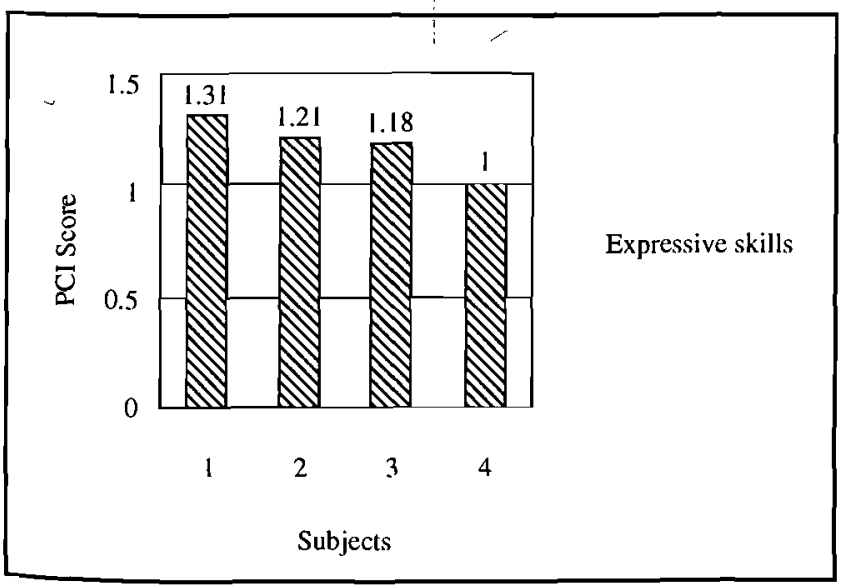

FIGURE 5: Rate of development for expressive language abilities $(n=4)$
The slower rate of development that three of the subjects displayed during intervention may be attributed to the fact that the instrument used to assess the cognitive development of the subjects, namely the DASI-II (Fewell \& Langley, 1984), is a screening instrument and not an in-depth diagnostic tool. Apart from the fact that the data derived from the DASI-II (Fewell \& Langley, 1984) might not be an accurate indication of the subjects' cognitive abilities, the benefit that the subjects received from early communication intervention for their cognitive development should be interpreted in conjunction with their progress in language development since the development of cognition and language cannot be distinguished before twenty four months of age (Rossetti, 1996).

During the pre-treatment assessment subjects two and three showed cognitive development levels one and two months above their chronological ages respectively (See Figures 2 and 3). These two subjects' cognitive development levels were equal or slightly above their chronological ages at the time of the post-treatment assessment. This indicates that, although their developmental rates seem to be slower during intervention than prior to intervention, their cognitive development is still within the normal limits for their chronological age.

In contrast with subjects two and three, subject four had a two month lag in her cognitive developmental level during the pre-treatment assessment (See Figures 2 and 3). She maintained this delay in her development during the intervention period and as a result her rate of development stayed the same. These results are confirmed by researchers who indicate that children with Pierre Robin sequence and an associated disorder have poorer developmental outcomes than those children with Pierre Robin sequence only (Pashayan \& Lewis, 1984; Shprintzen \& Bardach, 1995).

Subject one also had a slower rate of development during intervention than prior to intervention. During the pretreatment assessment his cognitive development level was equal to his chronological age (See Figures 2 and 3). At the time of the post-treatment assessment his cognitive development was, however, two months below his chronological age although his developmental quotient was still average. The fact that subject one showed a slower rate of cognitive development during intervention than prior to intervention may be attributed to the fact that he suffered trauma due to an accident causing a burning wound on his face, as Schoenbrodt \& Smith (1995) indicated that trauma may have a detrimental effect on development.

The results of the subjects' rate of cognitive development

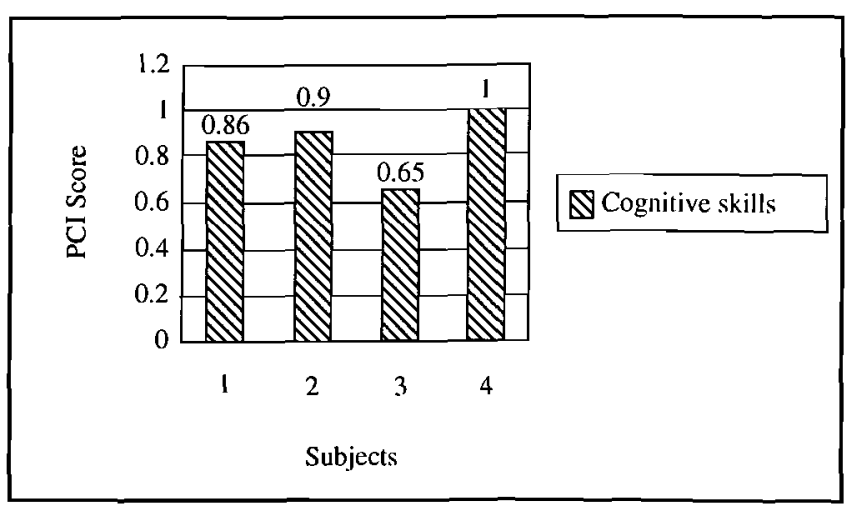

FIGURE 6: Rate of development for cognitive abilities ( $n=4)$ 
indicate the complex nature of early development. Although early language development and early cognitive development are interrelated (Rossetti, 1996), results indicate that three of the subjects derived benefit from early communication intervention for early language development, but not for cognitive development. This fact may either point to the need to increase the focus on the facilitation of cognitive development during early communication intervention or may indicate limitations in the CHRIB Evaluation Protocol (Louw \& Kritzinger, 1994).

The results of the subjects' developmental rate of receptive- and expressive language abilities, as well as cognitive abilities illustrate the effectiveness of the PCI (Wolery, 1983) as a measurement of the amount of child progress made in intervention. As the subjects were not matched a big difference existed between the ages of the subjects and the period of intervention each received varied considerably (See Table 2). The PCI (Wolery, 1983) yields a uniform numerical statement which accounts for individual differences, making it suitable for clinical and research purposes.

\section{SPEECH PRODUCTION ABILITIES}

Figure 7 indicates the development of the subjects' speech production abilities by comparing the number of consonants they produced at the pre-treatment assessment to the number of consonants they produced during the posttreatment assessment and table 3 illustrates the different consonants that each subject produced during the pre- and post-treatment assessments.

According to figure 6 and table 3 all the subjects showed

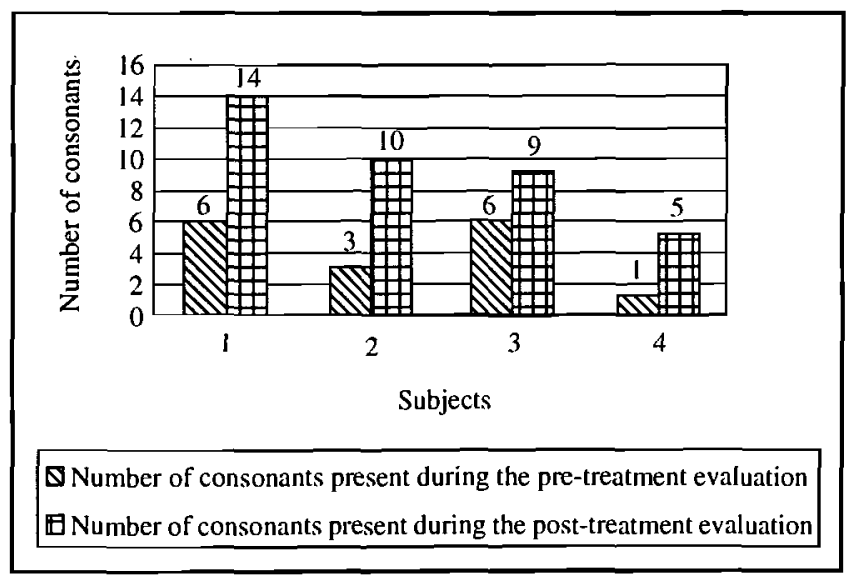

FIGURE 7: Development of phonetic repertoires for consonants $(n=4)$ development in their phonetic repertoires for consonants during the intervention period. Only one subject (S1) produced pressure consonants during the pre-treatment assessment and did not exhibit any indication of velopharyngeal incompetence during vocalization. This subject (S1) acquired eight consonants during the early communication intervention period of fourteen months (See Table 2). Subject four acquired four consonants during the early communication intervention period of five months (See Table 2), but although she acquired these consonants, her phonetic repertoire was marked by a limited use of pressure consonants during the pre-and post-treatment assessments (See Table 3). As the effect of natural maturation could not be accounted for in the analysis of subjects' consonant development, these results seem to indicate that the combined effect of natural maturation and the early communication intervention subjects one and four received, produced positive results.

Subject two acquired 7 consonants during the early communication intervention period of nineteen months (See Table 2). As is often observed in children with Pierre Robin sequence (McWilliams, et al., 1990), she displayed nasal emission during speech production as well as limited use of pressure consonants indicating velopharyngeal incompetence during both the pre-and post-treatment assessments (See Table 3). Although she attended the most early communication intervention sessions, she seemed to have derived limited benefit from early communication intervention for her speech production abilities.

Subject three acquired the least consonants during the intervention period ( 3 consonants over a 9 month period (See Table 2)) and also displayed nasal emission during speech production as well as limited use of pressure consonants indicating velopharyngeal incompetence during the pre-and post-treatment assessments (See Table 3). These results may be attributed to the fact that she only received one early communication intervention session during a nine month period and therefore she may not have received enough adequate stimulation for her speech production abilities.

Brodsky, Holt and Hue Ritter-Schmidt (1992) mention that few studies confirm the effectiveness of speech'therapy for velopharyngeal incompetence and conclude that the prognosis of children with velopharyngeal incompetence appears to be better if intervention starts early. The results of the subjects' speech production abilities emphasize the complexity of determining the effectiveness of speech therapy for velopharyngeal incompetence and suggest that the early presence of velopharyngeal incompetence may be an indication of a later delay and disorder in speech production abilities.

TABLE 3: The subjects' phonetic repertoires for consonants

\begin{tabular}{|c|c|c|}
\hline \multicolumn{2}{|c|}{ PHONETIC REPERTOIRES FOR CONSONANTS } \\
\hline Subject & Pre-treatment Assessment & Post-treatment Assessment \\
\hline $\mathbf{1}$ & {$[\mathrm{p}],[\mathrm{b}],[\mathrm{x}],[\mathrm{m}],[\mathrm{n}],[\mathrm{n}]$} & {$[\mathrm{p}],[\mathrm{b}],[\mathrm{t}],[\mathrm{d}],[\mathrm{k}],[\mathrm{g}],[\mathrm{w}],[\mathrm{v}],[\mathrm{s}],[\mathrm{x}],[\mathrm{h}],[\mathrm{m}],[\mathrm{n}],[\mathrm{n}]$} \\
\hline $\mathbf{2}$ & {$[\mathrm{h}],[\mathrm{m}],[\mathrm{n}]$} & {$[\mathrm{t}],[\mathrm{k}],[\mathrm{g}],[\mathrm{w}],[\mathrm{v}],[\mathrm{s}],[\mathrm{x}],[\mathrm{h}],[\mathrm{m}],[\mathrm{n}]$} \\
\hline $\mathbf{3}$ & {$[\mathrm{w}],[\mathrm{m}],[\mathrm{n}],[\mathrm{x}],[\mathrm{k}],[\mathrm{h}]$} & {$[\mathrm{p}],[\mathrm{t}],[\mathrm{k}],[\mathrm{w}],[\mathrm{v}],[\mathrm{x}],[\mathrm{h}],[\mathrm{m}],[\mathrm{n}]$} \\
\hline $\mathbf{4}$ & {$[\mathrm{h}]$} & {$[\mathrm{p}],[\mathrm{t}],[\mathrm{g}],[\mathrm{h}],[\mathrm{m}]$} \\
\hline
\end{tabular}


Subjects one, two and three had undergone surgery to repair their cleft palates at the time of the post-treatment assessment but subject four, who had a submucosal cleft, had not had surgery at the time of the post-treatment assessment. Only one subject (S1) produced pressure consonants and had no evidence of velopharyngeal incompetence during both the pre- and post-treatment assessments, whereas all the other subjects did not produce pressure consonants as part of their phonetic repertoires during the pre-treatment assessment and still showed limited use of pressure consonants during the posttreatment assessment. This may be an indication of the pervasive effect that Pierre Robin sequence has on the speech production abilities of children displaying this disorder even after surgery has been performed. These results may further point to the need for the use of a different approach towards speech production intervention for young children with Pierre Robin sequence displaying signs of velopharyngeal incompetence or it might indicate that the complexity of the disorder is not fully understood.

\section{CONCLUSION}

Guralnick (1997, p. xvi) indicates that the effectiveness of early intervention has been well documented and that the current challenge in efficacy research is not to establish whether early intervention is effective, but to 'determine what interventions work best, for whom, under what conditions and toward what ends'. The results of this study confirmed the general effectiveness of early communication intervention with young children with Pierre Robin sequence but raised specific concerns about programme features. The early communication intervention that the subjects received seemed to have had positive effects on their expressive language abilities and also on the receptive language abilities of two of the subjects. Only one subject seems to have derived adequate benefit from early communication intervention for his speech production abilities and a poor developmental rate was found for the cognitive abilities of the subjects.

The importance of regular early communication intervention sessions over an extended period of time was also emphasised by the results. The subjects who attended the most early communication intervention sessions over the longest periods of time, derived the most benefit. Guralnick (1997) advocates that early intervention sessions should be conducted once weekly but the current South African context poses a number of challenges to early communication intervention service delivery, such as geographical distribution of available services and a shortage of therapists trained in early intervention. The early communication intervention approach devised by Louw et al. (1997) for the South African context accounts for these challenges and indicates that sessions conducted once monthly are adequate. Authors concur, however, that early communication intervention should start as early as possible and continue until the development of the child is satisfactory (Louw \& Kritzinger, 1991; Rossetti, 1996; Guralnick, 1997).

The presence of a slight hearing loss due to otitis media may have influenced the effectiveness of early communication intervention regarding the subjects' receptive language abilities. In order to monitor the effect of the slight hearing loss accompanying otitis media on language development, it is suggested that effective practice should include periodic monitoring of hearing at least every three months (Kritzinger, Louw \& Hugo, 1996).

Subject four who was diagnosed with Pierre Robin sequence as well as an associated disorder, namely Velocardio-facial syndrome, attended only two early communication intervention sessions and it appears as if she derived limited benefit from therapy. These results concur with literature indicating that children with Pierre Robin sequence and an associated disorder have poorer developmental outcomes than children with Pierre Robin sequence only (Pashayan \& Lewis, 1984; Shprintzen \& Bardach, 1995). This fact emphasizes the need for individualised early intervention services for children with Pierre Robin sequence and an associated disorder and indicates that they may require more intensive services with the focus on strengthening their strong points and facilitating the weak areas in their development.

The fact that the subject with the associated disorder (Ss4), as well as moderate prematurity, showed the slowest rate of development for expressive and receptive language abilities, but maintained her rate of cognitive development and expanded her phonetic repertoire, emphasizes that the causes of a communication problem should be viewed according to a transactional model. The transactional model acknowledges the dynamic interaction between a child and his or her environment and allows for change over time (Rossetti, 1996). When this model is applied to young children with Pierre Robin sequence, who are at-risk for developing communication disorders, it becomes clear that there is not a direct linear cause-and-effect correlation between the number and magnitude of risk factors and the extend of delay in communication development (Kritzinger, Louw \& Hugo, 1996). The transactional model applied to early communication intervention service delivery to young children with Pierre Robin sequence implies that the clinician should view each child within the context of his or her individual strengths and weaknesses and that prognostic statements about the communication development of young children with Pierre Robin sequence should be made with care.

The PCI (Wolery, 1983) that was used to determine the amount of child progress, proved to be a valuable formula since it provided an accurate indication of the benefit that the subjects derived from the early communication intervention they received, by accounting for natural maturation as well as the child's rate of development prior to intervention. The new application of the PCI (Wolery, 1983) to determine the amount of child progress during intervention seems to be an appropriate way to determine the outcome of intervention and may be used in further research or as a clinical tool to provide outcome-based intervention.

The data derived from the PCI (Wolery, 1983) did not account for the synergistic nature of early development since the assumption that development occurs in a linear fashion underlies the construction of the PCI formula (Lee \& Khan, 1998). Although the PCI (Wolery, 1983) currently seems to be an appropriate way of determining child progress in early communication intervention programmes, the utilization of a new method to determine programme effectiveness might be necessary in the fulurc in order to account for the non-linear nature of early development (Lee \& Khan, 1998; Kritzinger, Louw \& Hugo, 1996).

The influence of variables related to child outcomes in early intervention are described by Lee \& Khan (1998) and 
Guralnick (1997) who conclude that early intervention is a dynamic process with a number of child, family/parent and programme variables potentially influencing the effectiveness of early intervention. They emphasize the need for future research in early intervention where variables are carefully controlled and where the complex correlation between child and family characteristics and programme features and outcomes is addressed (Guralnick, 1997; Lee \& Khan, 1998).

The quasi-experimental design of this study allowed for subjects to be selected without controlling all the variables related to child outcomes in early intervention (McBurney, 1994). The variables that could not be controlled in this study, such as age at programme entry, parents'age, parents' education level, the settings of the pre- and post-treatment assessments and the locus of service delivery could each have contributed or have a detrimental effect on the positive effects that were indicated in general by this study. It is clear that further efficacy research, where variables are controlled more carefully, is required to fully understand what constitutes best practice regarding service delivery to young children with Pierre Robin sequence.

The role of the speech-language therapist with children with craniofacial anomalies is described as 'assisting the child with craniofacial anomalies to achieve his or her maximum communication potential' (Brodsky et al., 1992, p.230). Speech-language therapists involved with young children with Pierre Robin sequence can fulfil this role by endeavouring to provide accountable and effective services to these children. Further research on the early communication development of young children with Pierre Robin sequence as well as the effectiveness of early communication intervention with this population will lead to greater insight into the complexity of the disorder and to more effective service delivery.

\section{REFERENCES}

Anderson, D., Nelson, J. \& Fowler, S. (1978). Developmental Assessment Schema. In Northcott, W.H. (editor), Curriculum Guide: Hearing Impaired Children $(0.3$ years) and Their Parents. Washington DC: The Alexander Bell Association for the Deaf, Inc.

Boston, B.O. (1994). Destiny is in the data. A wake-up call for outcome measures. American Speech-Language-Hearing Association, November, 35-38.

Brodsky, L., Holt, L. \& Hue Ritter-Schmidt, D. (1992). Craniofacial Anomalies: An Interdisciplinary Approach. New York: Mosby Year Book.

Bull, M.J., Givan, D.C., Sadove, A.M., Bixler, D. \& Hearn, D. (1990). Improved outcome in Pierre Robin sequence: Effect of multidisciplinary evaluation and management. Paediatrics, 86(2), 294-301.

Carney, A.E. (1996). Introduction to supplement on treatment efficacy: Part 1. Journal of Speech and Hearing Research, 39, S3-S4.

Caouette-Laberge, L., Bayet, B. \& Larocque, Y. (1994). The Robin sequence: Review of 125 cases and evolution of treatment modalities. Plastic and Reconstructive Surgery, 93(5), 934-942.

Elliot, M.A., Studen-Pavlovich, D.A. \& Ranalli, D.N. (1995). Prevalence of selected paediatric conditions in children with Pierre Robin sequence. American Journal of Paediatric Dentistry, 17(2), 106-111.
Fair, L. (1997). Vroeë Kommunikasie-ontwikkeling van Jong Kinders met Pierre Robin Volgpatroon. Unpublished B.Communication Pathology Research Report. University of Pretoria.

Fewell, R.R. \& Langley, M.B. (1984). Developmental Activities Screening Inventory. Austin: Pro-ed, Inc.

Friel-Patti, S. (1990). Otitis media with effusion and the development of language. Topics in Language Disorders, 11(1), 11-22.

Guralnick, M.J. (1997). The Effectiveness of Early Intervention. Maryland: Paul H. Brookes Publishing Co.

Handžič, J., Bagatin, M., Subotič, R. \& Cuk, V. (1995). Hearing levels in Pierre Robin syndrome. Cleft Palate Craniofacial Journal, 32(1), 30-36.

Kritzinger, A., Louw, B. \& Hugo, R. (1996). Early communication functioning of infants with cleft lip and palate. The South African Journal of Comnunication Disorders, 43, 77-84.

Lee, S. \& Khan, J.V. (1997). Measures of child progress and program effectiveness in early intervention. Infant-Toddler Intervention: The Transdisciplinary Journal, 7(4), 215-233.

Lee, S. \& Khan, J.V. (1998). Child progress and related variables in early intervention. Infant-Toddler Intervention: The Transdisciplinary Journal, 8(1), 83-101.

Louw, B. \& Hugo, R. (1987). Ouergesentreerde interaksie-terapie. SASHLA National Conference Abstracts. Johannesburg.

Louw, B. \& Kritzinger, A. (1991). Infants with Down Syndrome: description of an early intervention approach. The South African Journal of Conimunication Disorders, 38, 25-31.

Louw, B. \& Kritzinger, A. (1994). CHRIB Evaluation Protocol. Centre for Early Intervention in Communication Pathology, Department of Communication Pathology, University of Pretoria.

Louw, B., Hugo, R., Kritzinger, A. \& Pottas, L. (1997). Konımunikasie Intervensie vir 0-2 Jarige Hoërisiko-babas. Workshop presented by Centre for Early Intervention in Communication Pathology, Department of Communication Pathology, University of Pretoria, 13 June 1997.

McBurney, D.H. (1994), Research Methods (3rd edition). Pacific Grove, California: Brooks/Cole.

McWilliams, B.J., Morris, H.L. \& Shelton, R.L. (1990). Cleft Palate Speech. New York: Associated Press.

Oller, D.K., Eilers, R.E., Steffens, M.L., Lynch, M.P. \& Urbano, R. (1994). Speech-like vocalizations in infancy: an evaluation of potential risk factors. Journal of Child Language, 21, 3358 .

Owens, R.E. (1995). Language Disorders: A Functional Approach to Assessment and Intervention. Needham Heights: Allyn \& Bacon.

Pashayan, H.M. \& Lewis, M.B. (1984). Clinical experience with the Robin sequence. Cleft Palate Journal, 21(4), 270-276.

Rossetti, L.M. (1990). The Rossetti Infant-Toddler Language Scale. Illinois: Lingui Systems, Inc.

Rossetti, L.M. (1996). Comlnunication Intervention: Birth to Three. San Diego: Singular Publishing Group Inc.

Sadewitz, V.L. (1992). Robin Sequence: Changes in thinking leading to changes in patient care. Cleft Palate Craniofacial Journal, 29(3), 246-253.

SASHLA. (1997). Code of Ethics. Ethics and Standards Committee.

Savage, H.E. (1997). An early intervention guide to infants born with clefts. Infant Toddler Intervention: The Transdisciplinary Journal, 7(4), 271-284.

Schoenbrodt, L. \& Smith, R.A. (1995). Conınunication Disorders and Interventions in Low Incidence Pediatric Populations. San Diego: Singular Publishing Group Inc.

Shprintzen, R.J. \& Bardach, J. (1995). Cleft Palate Speech Management. A Multidisciplinary Approach. New York: Mosby Books Inc.

Wolery, M. (1983). Proportional change index: An alternative for comparing child change data. Exceptional children, 50(2), 167170 . 